\title{
ON INTERACTION OF A LIQUID FILM WITH AN OBSTACLE
}

\section{A. ZEMITIS}

Recently employed by Ventspils University College, Fraunhofer Institut Techno- und Wirtschaftsmathematik

Inzenieru 101, Ventspils, LV-3601, Latvia,

Gottlieb Daimler Strasse 49, 67663 Kaiserslautern, Germany

E-mail: zemitis@venta.lv

Received September 18, 2002

\begin{abstract}
In this paper are discussed mathematical models for the liquid film generated by impinging jets. These models describe only the film shape under special assumptions about processes. Attention is stressed on the interaction of the liquid film with some obstacle. The idea is to generalize existing models and to investigate qualitative behavior of liquid film using numerical experiments. G.I. Taylor [Proc. R. Soc. London Ser. A 253, 313 (1959)] found that the liquid film generated by impinging jets is very sensitive to properties of the wire which was used as an obstacle. The aim of this presentation is to propose a modification of the Taylor's model, which allows to simulate the film shape in cases when the angle between jets is different from $180^{\circ}$. Numerical results obtained by discussed models give two different shapes of the liquid film similar as in Taylors experiments. These two shapes depend on the regime: either droplets are produced close to the obstacle or not. The difference between two regimes becomes larger if the angle between jets decreases. Existence of such two regimes can be very essential for some applications of impinging jets, if the generated liquid film can have a contact with obstacles.
\end{abstract}

Key words: Impinging jets, liquid film, obstacle, simulation

\section{INTRODUCTION}

Recently impinging jets are used as impinging-jet injectors for droplet generation $[3 ; 4 ; 5]$. The main characteristics of the impinging jets, which are interesting for developers of corresponding devices, are the shape of the liquid film and the droplet distribution. Fundamentals of the liquid sheet formed during impinging of jets can be found in papers of Taylor $[8 ; 9 ; 10 ; 11]$. It was shown there that the shape of a liquid film is dependent on the properties 
of symmetrical and antisymmetrical waves in such films. Taylor found conditions for stationary antisymmetrical waves in a moving sheet. He derived that waves, which can remain at rest, can be represented in special cases as cardioids. A smart analysis of the wave instabilities in the liquid sheet was done by N. Dombrowski and W.R. Johns [2]. They investigated also the size of ligaments and drops created during such processes. More detailed literature overview about earlier investigations regarding sheet form and droplet distribution can be found in the sources $[3 ; 5 ; 6]$. A framework for the simulation of the impinging jets was done by E.A. Ibrahim and A.J. Przekwas [3]. They proposed prediction models of the film form, droplet size and distribution. In [1] the methods of Dombrowski and Johns for fan-spray nozzles regarding to droplet size are transferred to impinging jets. In [5] atomization characteristics of sheets formed by laminar and turbulent impinging jets are studied experimentally. They propose some semi-empirical model for the droplets. In [6] an experimental study of the film thickness for impinging jets is presented.

In the practice there exist devices, where a contact of the liquid sheet with some surfaces can not be avoided. Taylor [10] did analysis about the interaction of a wire with the liquid sheet. Other authors mainly are working with free liquid sheets. Taylors results about interaction of the liquid film with wires are very important. He proposed that the shape of a disturbed liquid film by a small obstacle will be determined by antisymmetrical waves which can remain at rest. He observed two possible development of the film boundary, in dependence of the wire diameter and wetability.

It can be supposed that these results contain very deep physical phenomena, which need to be investigated. These phenomena can have a significant influence on the functionality of real devices based on impinging jets. In the paper there are investigated regimes where assumptions about Taylors cardioidal waves are fulfilled.

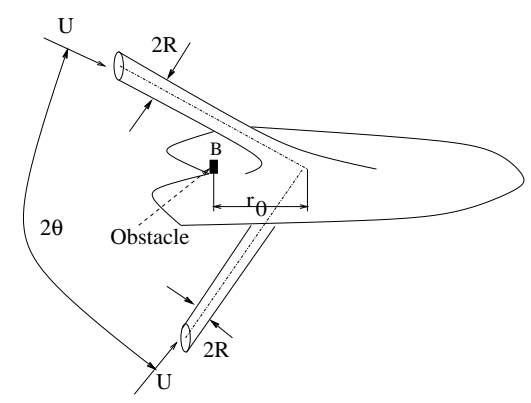

Figure 1. Interaction of the liquid film formed by impinging jets with an obstacle. Point $\mathrm{B}$ will also later show the position of obstacle.

The principal scheme of the droplet generation process by impinging jets can be seen in Fig. 1. Two impinging jets with the radius $R$ and with velocity $U$ build a liquid film. Point B characterizes the position of an obstacle. $r_{0}$ is the distance from the obstacle to the stagnation point (see also Fig. 2). 
Droplets can be generated on the film boundary. Different shapes of the film can be obtained in dependence of the angle between jets $(2 \theta)$.

Taylor proposed mathematical models and did experiments for the case $\theta=\pi / 2$. For the case $\theta \neq \pi / 2$ Taylor gave a suggestion for a model [11], but it was not fully determined (more about this in Section 3.). A possible way for solving the problem in the case of free liquid films proposed Ibrahim et. al. [3]. This model gives the shape of the liquid film, if parameters of liquid jets are given: radius $\mathrm{R}$, inclination angle $\theta$, surface tension of the liquid $\sigma$ and density of the liquid $\rho_{l}$. The main part of this model is briefly described in subsection 3.1. It is important to note that Ibrahim's et. al. model does not allow to put an obstacle which would change the shape of the film. We propose to use some ideas of Ibrahim et. al. for overcoming of the insufficient determination of the model [11] and for further development of models given in [9]. It will allow to account influence of an obstacle on the film shape for different angles $\theta$. Taylor investigated interaction of the liquid film with a wire, if the angle $\theta=90^{\circ}$. He changed the diameter and the properties of wetability for the wire and observed experimentally different behavior of the liquid film and the droplet generation process. Taylor did not give mathematical models for all possible situations, but for two processes the corresponding models were proposed. One is so called cardioid model and it corresponds to the case, if droplets are produced already in the vicinity of the obstacle. The boundary of the liquid film in this case is described by two cardioids, which start from the obstacle and turn in to a circle with some limiting radius (we will call it as $R_{\max }$ ).

For the case when droplets are not produced in the vicinity of obstacle, Taylor wrote equations [6, p. 13], but did not solve them. It is necessary to note that these Taylor's models were derived for the case $\theta=90^{\circ}$. Our aim is to modify Taylor's models for inclined jets $\left(\theta \neq 90^{\circ}\right)$ and to do numerical experiments. The main questions are:

- Can there exist two different solutions for the film shape in the case of inclined jets, if we take as basis Taylor's models for $\theta=90^{\circ}$ ?

- What properties can these solutions have?

If also in the case $\theta \neq 90^{\circ}$ similar effects are possible as Taylor observed, then additional experimental and theoretical work on this area is required. Such effects can significantly influence the quality of devices, which use impinging jets in technological processes. We want to stress that our work has a qualitative character, because no direct contact to corresponding experiments was possible. Obtained differential equations are solved numerically by using code "DDASSL" from Lawrence Livermore National Laboratory.

\section{MODELS FOR FILM SHAPE AT $\theta=90^{\circ}$}

Taylor analyzed in his paper [10] development of perturbation in the thin liquid sheets in the case when a vertical jet impacts on a flat impacter. The 
flow direction is perpendicular to the impacter and it corresponds to impinging jets, if the angle between jets is $2 \theta=180^{\circ}$. There is also more detailed information given about the model. The most important assumptions are the following: the flow in the film from the stagnation point is radial and potential and the liquid velocity in the radial direction is equal to the velocity of the jet $U$. The Fig. 1 shows that the droplet generation process is a complex 3D process. The analyzed models will describe the shape of the liquid film in $2 \mathrm{D}$ (as a view from above).

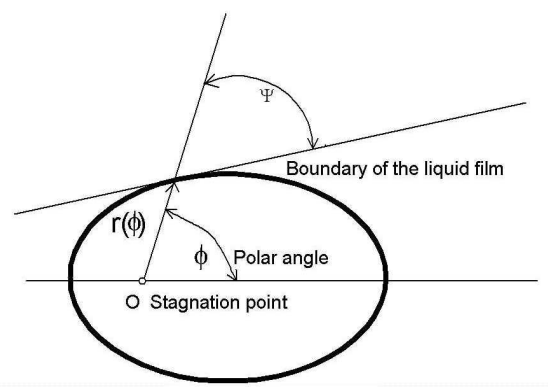

Figure 2. The 2D view of the liquid film. Angle $\phi$ is the polar angle, but $\Psi$ is angle between the radius vector and the tangent to the boundary curve.

The boundary of the liquid film will be described in polar coordinates $(r, \phi)$ where the point $O$ corresponds to the stagnation point. In the Fig. 2 the boundary of the liquid film is shown as a curve around the stagnation point $O$. The boundary will be represented as a function $r=r(\phi)$. Here an additional angle is important: the angle $\Psi$ between the radius vector and the tangent to the boundary curve. It is well known that [11, p. 1392]:

$$
\tan \Psi(\phi)=\frac{r_{e}(\phi)}{r_{e}^{\prime}(\phi)},
$$

where $r^{\prime}(\phi)=\frac{d r}{d \phi}$. This property of the tangent for curves in polar coordinates will be used later several times. It is necessary to remember that in general the model involves three angles: $\theta, \phi$ and $\Psi$.

The process of droplet generation depends on Weber's number $W_{e}[3]$ :

$$
W_{e}=\frac{\rho_{l} U^{2} R}{\sigma},
$$

where $\rho_{l}, \sigma$ are density and surface tension of the liquid.

Taylor found that anti-symmetrical waves are responsible for spreading of the disturbances and that the velocity of these waves are independent of the wavelength (for low Weber's numbers, $W e<500$ ). A very important property is the following: if the sheet is moving with the velocity $U$, then the waves will be at rest in space if lines of constant phase are at the angle $\Psi$ to the direction of flow, where: 


$$
\sin \Psi=\left(\frac{2 \sigma}{\rho_{l} h U^{2}}\right)^{0.5}
$$

and $h$ is the thickness of the liquid sheet. In fact the equation (1.3) is a condition when the capillary forces, which act at right angles to the boundary, are equal to the normal component of inertial forces. Surface forces are growing together with the radial distance from the stagnation point. The inertial force remains constant, because the velocity along streamlines is constant and the flow is assumed to be potential.

Taylor rewrote the equation in other form:

$$
\sin ^{2} \Psi=\frac{2 \sigma}{\rho_{l} h U^{2}}=\frac{4 \pi \sigma r}{\rho_{l} U Q}=\frac{r}{R_{\max }}
$$

where $Q=2 \pi r h U$ is the volumetric flow rate per second and $R_{\max }=$ $\rho_{l} U Q / 4 \pi \sigma$. This form of equation allows better understanding of the model. Here $R_{\text {max }}$ is the limiting radius. For $r>R_{\text {max }}$ the liquid film can not remain continuous (the surface forces will destroy the liquid film). The liquid film can be continuous at the distance $R_{\max }$ from the stagnation point only if the radius vector is perpendicular to the boundary curve $\Psi=\pi / 2$ (this is true for the circle with radius $\left.R_{\max }\right)$. As Taylor observed experimentally, the boundary of the liquid film becomes a circle, if there are no obstacles interacting with the liquid film.

By using the formula (1.1) the angle $\Psi$ can be excluded from the equation (1.4) and a differential equation can be obtained:

$$
\left(\frac{d r_{e}}{d \phi}\right)^{2}=R_{\max } r_{e}-r_{e}^{2}
$$

In polar coordinates $(r, \phi)$ Taylor [9] found that cardioid curves $r_{e}(\phi)$ :

$$
r_{e}(\phi)=\frac{R_{\max }}{2}\left(1-\cos \left(\phi-\phi_{0}\right)\right)
$$

fulfill the equation (1.5), where $\phi_{0}$ is a constant, which represents the angular position of an arbitrary point from which the wave is starting. As expected from the previous discussion, there exists the additional solution:

$$
r_{e} \equiv R_{\max }
$$

In Fig. 3, 8 cardioids with $R_{\max }=1$ and different values for $\phi_{0}$ can be seen. Also a circle with the radius 1 is drawn. It is important to stress that each cardioid touches the circle if $\phi_{n}=\phi_{0}+2 \pi n$ and $n$ is an integer. At these points for both curves (1.6) and (1.7) the derivatives are equal to zero:

$$
r_{e}^{\prime}\left(\phi_{n}\right)=0
$$




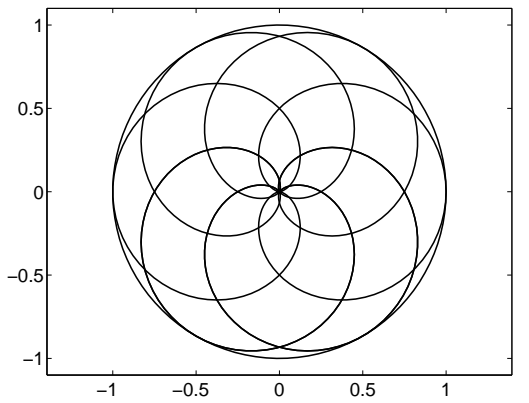

Figure 3. 8 cardioids $\left(R_{\max }=1, \phi_{0}=\pi / 6,2 \pi / 6, \ldots, 8 \pi / 6\right)$ and a circle with the radius 1.

From the mathematical point of view there is no unique way for continuation of the solution if it touches the circle $r_{e} \equiv R_{\max }$. But it is well known that the surface tension tends to minimize the curvature of free boundaries [12, pp. 110 - 113]. Then it follows, that the solution of the equation (1.5) from some point on the circle with radius $R_{\text {max }}$ in flow direction physically can be continued only by the formula (1.7) (if there are not any additional disturbances of the liquid film).

If there is no interaction with obstacles, then the shape of the film is a circle with the radius $R_{\max }$. If there is an obstacle, then the shape of the film consists of two parts. One part of the boundary is build by two limiting cardioids, which connect the obstacle and the circle with radius $R_{\max }$. The other part is a segment of the circle with radius $R_{\max }$. An example of the solution (only one half of the curve is drawn) in the case of interaction with an obstacle (point B) can be seen in Fig. 4 (solid line). Also in more general case $\theta \neq 90^{\circ}$ Taylor [11] discussed the tendency of the liquid film to achieve the unique critical curve which corresponded to "a position at which an edge could be established without using an obstruction to hold it in position" [7, p. 13].

\section{TAYLORS EDGE BY $\theta=90^{\circ}$}

Taylor [10] has investigated interaction of the liquid film with some obstacle (a wire). The result was very sensitive to the properties of the wire (wet-ability, diameter). In some cases he observed experimentally that the properties of disturbed film can be different. There exist such perturbations as on the one part of the film boundary droplets are not produced. The radial flow from the impact point changes on the film boundary direction, and the liquid flows there in the tangential direction. At the same time this fact does not have great influence on the other part of the film flow. As the result there exists a point on the film boundary where two types of boundary meet each other (on one side droplets are produced but on the other not). Mathematically this point corresponds to the switching point between different models and 
we will mark in Figures this point by the letter " $A$ ". In Taylor's figures of experiments point A can be observed as an edge on the film boundary. Close to this point the velocity vector has different directions.

Taylor's model [10] for the liquid film, if droplets are not produced on the corresponding boundary, it is interesting from two points of view:

- the model will be used later as a base for modifications if the liquid jets are not perpendicular to the film plane,

- numerical solutions can be compared qualitatively with the Taylor's observations.

\subsection{Model for the film without droplets}

In this subsection the Taylor's model [10] is used describing the liquid film boundary if droplets are not produced there. We will call it an extended model.

The model involves parameters which are defined on the film boundary and depend only on the polar angle $\phi$. Taylor has introduced a scalar parameter $q$. The value $q U$ characterizes the tangential speed of the liquid on the film boundary. Taylor's equations [10] are written here in the case if the obstacle has a position at $\left(r_{0}, \pi\right)$ (point $\left.\mathrm{B}\right)$ :

$$
\left\{\begin{array}{l}
\frac{d}{d \phi}((\pi-\phi) q)=-\cos \Psi \\
1-\frac{R_{\max }}{r_{e}} \sin ^{2} \Psi=(\pi-\phi) q \frac{R_{\max }}{r_{e}}\left(\frac{d \Psi}{d \phi}+1\right) \sin \Psi
\end{array}\right.
$$

where again $\left(r_{e}(\phi), \phi\right)$ are polar coordinates of the film boundary, $R_{\max }$ is the limiting radius for liquid film (was explained in connection to the formula (1.4)). By using (1.1) a system of ordinary differential equations for $\left(r_{e}(\phi), q(\phi)\right)$ can be derived. It is convenient to have a system of first order equations. Therefore an additional function $w=d r_{e} / d \phi$ is introduced, and a system for unknowns $\left.r_{e}(\phi), w(\phi), q(\phi)\right)$ can be written:

$$
\left\{\begin{array}{l}
\frac{d r_{e}}{d \phi}=w \\
w^{2}+r_{e}^{2}-R_{\max } r_{e}=\frac{R_{\max }}{r_{e}} q(\pi-\phi) \sqrt{\frac{r_{e}^{2}}{w^{2}+r_{e}^{2}}}\left(2 w^{2}+r_{e}^{2}-r_{e} \frac{d w}{d \phi}\right) \\
(\pi-\phi) \frac{d q}{d \phi}-q=-\sqrt{\frac{w^{2}}{w^{2}+r_{e}^{2}}}
\end{array}\right.
$$

The initial values are also proposed by Taylor [10], and in our case it means:

$$
r_{e}(\pi)=r_{0}, \quad w(\pi)=-r_{0} \sqrt{\frac{R_{\max }-r_{0}}{r_{0}}}, \quad q(\pi)=\sqrt{\frac{R_{\max }-r_{0}}{R_{\max }}} .
$$




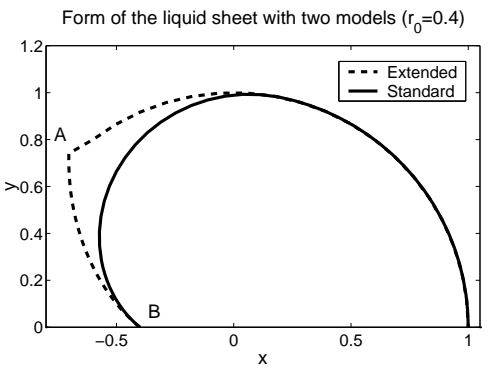

Figure 4. Simulation results corresponding to Taylors experiments, if droplets are produced on the whole edge (solid line) or only on one part (dotted line between B and A shows the part where droplets are not produced )

The problem (2.2) - (2.3) can be solved numerically for decreasing values of $\phi \leq \pi$. The solution process must be realized stepwise for discrete values of angle $\phi_{k}, k=0,1, \ldots$, because we have to control the values of $r_{e}\left(\phi_{k}\right)$. If $r_{e}$ for some angle $\phi_{k 0}$ becomes greater than $R_{\max }$, then it is necessary to turn back to the angle $\phi_{k 0-1}$. In this way by using different discretizations we can estimate, with different accuracy, the switching point $\phi_{A}$, which corresponds to the point $A$. At this point $r_{e}\left(\phi_{A}\right)=R_{m a x}$. If the polar coordinate of the edge $r_{e}$ reaches $R_{\text {max }}$, then droplets are produced and remaining part of the film has a constant polar coordinate $r_{e}=R_{\max }$ for $\phi \in\left(\phi_{A}, 0\right)$. In the model the parameter $R_{\max }$ contains all flow parameters and the solution depends on the non-dimensional parameter $r_{0} / R_{\max }$. Therefore it can be assumed that $R_{\max }=1$ and the values of $r_{0}$ can be varied.

\subsection{Results}

In Fig. 4 the results of simulations obtained by two models are presented. Assume that: $R_{\max }=1$ and $r_{0}=0.4$. The solid line corresponds to the solution $(1.6)-(1.7)$ and is referred as standard solution. Here only one half of the symmetric solution is shown.

The standard solution shows the shape of the liquid film if droplets are produced on the whole boundary.

The dotted line (noted as "extended" solution) corresponds to the model from subsection 2.1, when droplets are not produced near the obstacle. The part of the dotted line from the point B $(x=-0.4)$ to the point A corresponds to the solution of the problem $(2.2)-(2.3)$. The continuation of the line is described by $r_{e}=R_{\max }=1$. Here the conditions for the droplet generation are fulfilled. As it was mentioned before, Taylor observed experimentally two types of the liquid film in dependence of properties of the wire. In the paper [6,p.316] is written about the case when droplets are produced : 'If the obstruction causes the sheet to separate into streams bounded by two edges, these edges will also assume the cardioid form provided that they immediately 
broke up into drops ...". In the same paper [6, p. 317] Taylor wrote about the case if droplets are not produced: "It will be noticed also that the form of the edge is quite different from a cardioid which would have had greater curvature". The numerical results allow to compare both types of solutions. The "standard" solution is formed by a part of a cardioid and a circle with the radius $R_{\max }$. The "extended" solution, where droplets are not produced, is quite different from the cardioid and has a smaller curvature as a cardioid. Visually this solution is similar to the first picture in Fig.III6 [6]. Unfortunately it was not possible to obtain a quantitative comparison between the experimental and simulated curves. But for the praxis it is very important to know also the qualitative behavior of the disintegration process. Specially it is important to know in the case $\theta \neq 90^{\circ}$, because in this case the undisturbed shape of the liquid film is not a circle.

\section{NEW MODEL FOR $\theta \neq 90^{\circ}$}

In previous Section two different solutions for the shape of the liquid film were obtained, if the angle $\theta=90^{\circ}$. Our aim is to answer the following question: is it possible to get similar results in the case of inclined jets? For this purpose mathematical models are necessary, which can work for inclined liquid jets and allow to account an obstacle.

For free liquid films in the case of inclined jets there exists a model, proposed by Ibrahim et. al. [3]. We will refer later to this model as to model-I. As it was mentioned in the introduction, by using model-I obstacles cannot be directly accounted. Therefore a modification of the model-I is needed. By using the modification it would be possible to estimate the film shape in the case when droplets are generated on the whole film boundary.

For the regime, when droplets are not produced near the obstacle, the Taylor's model (2.1) has to be modified.

\subsection{Modification of the model-I}

The aim now is to obtain differential equation, which allows to construct the shape of the liquid film starting from any point close to the impact point. We noted in the introduction that Taylor had ideas for the mathematical model for the case of inclined jets [11]. In that paper Taylor noticed existence of an limiting radius (dependent on inclination $\theta$ and also on polar angle $\phi$ ). Outside of this radius no one antisymmetrical wave can remain at rest (the liquid film will be destroyed by capillary forces). Taylor proposed to find this dependence experimentally. We will define the limiting curve by $R_{\max }(\theta, \phi)$. In fact, Ibrahim et. al. constructed a model [3], where the limiting curve $R_{\max }(\theta, \phi)$ is determined. It is necessary to remark, that the model [3] contains one more assumption as necessary. If we use one assumption less and instead of this apply the geometrical property (1.1), then it is possible to derive a differential equation for the shape of the liquid film. Differential equation allows to start 
the boundary curve at any point. It will be referred to the modified Ibrahim's et. al. model as to model-IM.

The model-IM includes the greatest part of steps from model-I, which is explained in [3]. Here this model will be only briefly described, because the difference from the original one is very little: we account the geometrical property (1.1). The main steps of the Ibrahim's et. al. model (model-I) are the following:

- Estimation of the parameter $\beta$, which depends on $\theta$ (this angle characterizes the inclination of the liquid jets):

$$
\cos \theta=\left(\frac{e^{\beta}+1}{e^{\beta}-1}\right) \frac{1}{1+(\pi / \beta)^{2}} .
$$

- Radius of the circle $r_{i}$, where the initial thickness of the sheet is defined ( $R$ is the radius of the liquid jet):

$$
r_{i}=\frac{R}{\sin \theta} .
$$

- The initial thickness of the sheet $h_{i}(\phi, \theta)$ at the radius $r_{i}$ ( $\phi$ is the polar angle in the film plane):

$$
h_{i}(\phi, \theta)=\beta R \sin (\theta) /\left(e^{\beta}-1\right) e^{\beta(1-\phi / \pi)} .
$$

- The thickness of the sheet $h(r, \phi, \theta)$ at any radial $r$ and angular position $\phi$ for different inclinations $\theta$ :

$$
h(r, \phi, \theta)=h_{i}(\phi, \theta) \frac{r_{i}}{r} .
$$

- Estimation of the thickness $h_{e}(\phi, \theta)$ of the edge can be done by using:

$$
h_{e}(\phi, \theta)=\frac{2 \sigma}{\rho_{l} U^{2} \sin ^{2} \psi} .
$$

and also by (3.4):

$$
h_{e}(\phi, \theta)=h\left(r_{e}, \phi, \theta\right)=h_{i}(\phi, \theta) \frac{r_{i}}{r_{e}},
$$

where $r_{e}=r_{e}(\phi, \theta)$ describes the boundary of the liquid film.

This part of the model-I is sufficient for the estimation of the film shape. For inclined jets all characteristic parameters of the liquid film depend on $\theta$. For shortening of terms this parameter will be omitted in the next expressions. From previous dependencies it can be derived:

$$
\sin ^{2}(\Psi(\phi))=\frac{2 \sigma\left(e^{\beta}-1\right) r_{e}(\phi)}{\rho_{l} U^{2} \beta R^{2} e^{\beta\left(1-\frac{\phi}{\pi}\right)}} .
$$


Similar as in (1.4) $\tilde{R}_{\text {max }}=\tilde{R}_{\text {max }}(\phi, \theta)$ can be introduced (we will omit $\theta$ ):

$$
\tilde{R}_{m a x}(\phi)=\frac{\rho_{l} U^{2} \beta R^{2} e^{\beta\left(1-\frac{\phi}{\pi}\right)}}{2 \sigma\left(e^{\beta}-1\right)} .
$$

Now the equation (3.7) can be rewritten in the form

$$
\sin ^{2}(\Psi(\phi))=\frac{r_{e}(\phi)}{\tilde{R}_{\max }(\phi)} .
$$

Formally in (3.7) there are two unknowns $r_{e}(\phi)$ and $\Psi=\Psi(\phi)$. But because of formula (1.1) the following differential equation can be derived instead of (3.9):

$$
\frac{r_{e}^{2}(\phi)}{\left(\frac{d r_{e}(\phi)}{d \phi}\right)^{2}+r_{e}^{2}(\phi)}=\frac{r_{e}(\phi)}{\tilde{R}_{\max }(\phi)} .
$$

Equation (3.10) is an ordinary differential equation with respect to the function $r_{e}(\phi)$. This function describes the shape of the liquid film, if droplets are produced on the film edge due to anti-symmetrical waves. This differential equation can be solved numerically, if an initial value for $r_{e}$ is given. Now the model-IM is complete and it is possible to estimate the film boundary starting from the position of the obstacle (point B). It is clear that the position of the obstacle must be chosen not to be far from the stagnation point: $r_{0} \leq$ $R_{\max }(\phi)$.

\subsection{The case if droplets are not produced}

The most interesting question is - how to modify the Taylor's model (2.2) (2.3) for the case if are not produced droplets close to the obstacle.

Taylor did his investigations about film edges, where no drops are produced in the case $\theta=90^{\circ}$. An interesting question is about such effect for inclined jets, but for solving of this problem the model (2.2) - (2.3) cannot be directly applied. For Taylor it was important that the right hand side of the equation (III.6) does not depend on the angle $\phi$. Now this is not true.

In Taylors investigation the parameter $R_{\max }$ is a constant. For inclined jets a new parameter $\tilde{R}_{\max }$ dependent on $\phi$ and $\theta(3.8)$ is introduced. During derivation of equations the steps from [10] are used as basis. Taylor takes as an important reference the value $r=R_{\max }$. Now other constant parameter must be used. If $\theta$ is fixed then $r_{i}$ is a constant (see formula (3.2)). On the circle with radius $r_{i}$ the initial thickness of the liquid sheet $h_{i}(\phi)(3.3)$ is defined. For the derivation of the model there can be used the fact that the function $h_{i}(\phi, \theta)$ can be integrated in a simple way (we will omit $\theta$ ):

$$
\int h_{i}(\phi) d \phi=-\frac{\pi}{\beta} h_{i}(\phi)+C
$$


where $C$ is some constant.

Assume that the position of the obstacle is $\left(r_{0}, \pi\right)$, then the equation corresponding to Taylors equation (III.7) can be written as follows:

$$
\frac{\pi}{\beta}\left(h_{i}(\phi)-h_{i}(\pi)\right) \frac{d q}{d \phi}-h_{i}(\phi) q=-h_{i}(\phi) \cos \Psi,
$$

Instead of the Taylors equation (III.8) the following equation can be derived:

$$
2 \sigma-\rho_{l} U^{2} h_{e}(\phi) \sin ^{2} \Psi=\frac{\rho_{l} r_{i} \pi U^{2} q}{\beta}\left(h_{i}(\phi)-h_{i}(\pi)\right)\left(\frac{d \Psi}{d s}+\frac{d \phi}{d s}\right) .
$$

By using $\tilde{R}_{\max }(\phi)$ and the definition of the angle $\Psi$ the system of equations can be formulated:

$$
\begin{aligned}
& \frac{d r_{e}}{d \phi}=w, \quad \phi<\pi, \\
& \frac{\pi\left(\tilde{R}_{\max }(\phi)-\tilde{R}_{\max }(\pi)\right) q}{\beta r_{e}} \sqrt{\frac{r_{e}^{2}}{r_{e}^{2}+w^{2}}}\left(2 w^{2}+r_{e}^{2}-r_{e} \frac{d w}{d \phi}\right)= \\
& \quad w^{2}+r_{e}^{2}-\tilde{R}_{\max } r_{e}, \quad \phi<\pi, \\
& \frac{\pi}{\beta}\left(h_{i}(\phi)-h_{i}(\pi)\right) \frac{d q}{d \phi}-h_{i}(\phi) q=-h_{i}(\phi) \sqrt{\frac{w^{2}}{w^{2}+r_{e}^{2}}}, \phi<\pi .
\end{aligned}
$$

This is a system for three variables $\left(r_{e}(\phi), w(\phi), q(\phi)\right)$. The initial values are estimated in a similar way as in [10]

$$
r_{e}(\pi)=r_{0}, \quad w(\pi)=-r_{0} \sqrt{\frac{R_{\max }(\pi)-r_{0}}{r_{0}}}, q(\pi)=\sqrt{\frac{\tilde{R}_{\max }(\pi)-r_{0}}{\tilde{R}_{\max }(\pi)}} .
$$

This model can be applied while

$$
r_{e}(\phi) \leq \tilde{R}_{\max }(\phi)
$$

and it means that on the corresponding part of the edge the droplets are not produced. In real simulations instead of the condition (3.17) some other condition is used. The switching to other model is done if $r_{e}(\phi)>0.99 \tilde{R}_{\max }(\phi)$ (criterion for the switching point $A$ ).

Assume that the switching of models has to be done at $\phi=\phi_{A}$. Then for $\phi<\phi_{A}$ the model based on equation(3.10) must be used. The corresponding mathematical problem can be formulated as follows: 


$$
\begin{aligned}
& \frac{r_{e}(\phi)}{d \phi}=-\sqrt{\tilde{R}_{\max }(\phi) r_{e}(\phi)-r_{e}^{2}(\phi)}, \quad \phi_{A}>\phi>0, \\
& r_{e}\left(\phi_{A}\right)=0.99 \tilde{R}_{\max }\left(\phi_{A}\right) .
\end{aligned}
$$

The model describes the boundary of the liquid film where droplets are produced. To the complete model (3.13) - (3.19) will be referred to as modelTI.

\section{NUMERICAL EXPERIMENTS}

In the previous Section three models for the shape estimation of the liquid film were introduced. To remind, they were as follows. The model-I is the model from the paper [3] and it is defined for free liquid films. The model-IM is a modification of the model-I, which was done in previous Section. This model allows to simulate the shape of the liquid film if droplets are produced on the whole boundary for different inclinations $\theta$. With this model the position of the obstacle can be accounted. The model-TI contains two parts and is proposed for the case if droplets are not produced close to obstacle. During the solution of the problem it is necessary to estimate the point $A$, at which the other model must be started. The aim of numerical experiments is to investigate different regimes for droplet generation in the case of inclined jets. The most interesting question is: can the model-TI really produce a solution which consists of two parts (existence of the similar edge $A$ as in Fig. 4)? The other question is: how do the parameters of liquid jets influence the position of the point $A$ ?

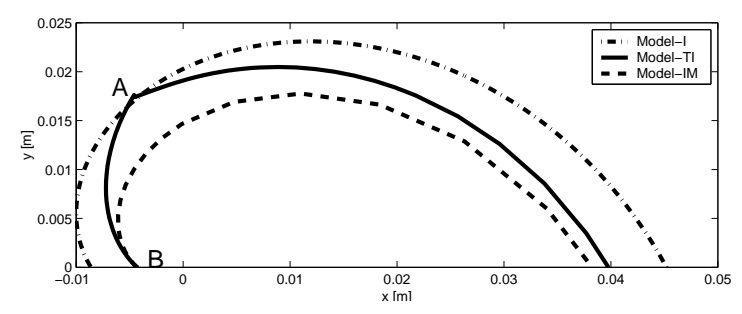

Figure 5. Simulation results with the model-TI, model-I and model-IM for inclined jets $\left(\theta=70^{\circ}\right)$.

In simulations the following parameters are fixed: $U=2.49 \mathrm{~m} / \mathrm{s}, \sigma=$ $0.073 \mathrm{~N} / \mathrm{m}, R=0.75 \mathrm{~mm}$. For the angle $\theta$ the values: $\theta=70^{\circ}, \theta=60^{\circ}$ and $\theta=45^{\circ}$ were chosen. The obstacle has the polar coordinate $r_{e}(\pi)=$ $0.5 \tilde{R}_{\text {max }}(\pi, \theta)$.

The simulated results are shown in Fig. 5-7. Each figure contains 3 curves, obtained by model-I, model-TI and model-IM. 


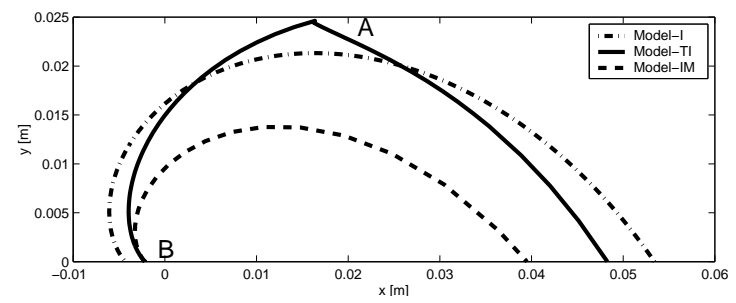

Figure 6. Simulation results with the model-TI, model-I and model-IM for inclined jets $\left(\theta=60^{\circ}\right)$.

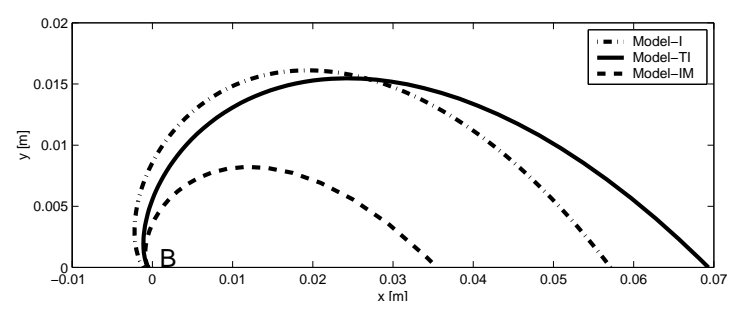

Figure 7. Simulation results with the model-TI, model-I and model-IM for inclined jets $\left(\theta=45^{\circ}\right)$. For given parameters the switching point A does not exist.

The corresponding curve to model-TI consists on two parts. First part of the corresponding curve (the solid line between B and A) is obtained by the modified Taylors model (3.13) - (3.16). At that part the droplets are not produced. The curve starts at the point B with $r_{e}(\pi)=0.5 \tilde{R}_{\max }(\pi, \theta)$ because of the obstacle. If at some $\phi_{A}$ the radius $r_{e}\left(\phi_{A}\right)>0.99 \tilde{R}_{\max }\left(\phi_{A}, \theta\right)$, then for the rest the model-IM (3.18)- (3.19) is used. At the point $A$ an edge is formed (similar as in Taylors experiments in the case $\theta=90^{\circ}$ ).

In Fig. 5 the results for $\theta=70^{\circ}$ can be seen. The solid line shows the results obtained by the model-TI. For this $\theta$ switching point can be very well observed (point A). Both other curves produced by model-I and model-IM are relatively close to the solid line. But it is necessary to stress that there are large qualitative differences. Model-I and model-IM assume that droplets are produced on the whole boundary of the liquid film. Model-TI proposes that on the first part (the solid line between B and A) no droplets are produced.

If the angle $\theta$ decreases (Fig. 6 corresponds to the angle $\theta=60^{\circ}$ ), then the point $\mathrm{A}$ is moving to the right. It means that in some cases on large part of the liquid film no droplets are produced. For given parameters the qualitative and quantitative difference between two possible regimes becomes larger.

If the same model parameters are used as previously but only the angle $\theta$ is changed to $45^{\circ}$ (Fig. 7), then the model-TI cannot fulfill condition $r_{e}(\phi)>$ $\tilde{R}_{\text {max }}(\phi)$ and the point $\mathrm{A}$ is not built. It means that droplets can be produced only at the end of the film (the polar angle $\phi=0$ ). If the models are true, 
then in this case two very different regimes of the liquid film must be observed (in dependence of wire properties):

- droplets are produced on the whole boundary of the liquid film,

- droplets are produced only on the end of the liquid film.

It is clear that in both cases spectra of generated droplets must be also very different. From this point of view investigation of reasons for two different regimes would be very important for real applications.

\section{CONCLUSIONS AND OUTLOOK}

Interaction of the liquid film with obstacles can lead to interesting phenomena as Taylor already observed. Droplets can be generated near the contact point with the obstacle or not in the dependence of properties of the obstacle. In the paper some models for the shape estimation of the liquid film are proposed and corresponding numerical solutions are obtained.

Two types of solution produced by Taylor's model agree qualitatively with Taylor's experiments. If close to the obstacle droplets are not generated, then the simulated boundary curve has an edge (point $A$ in Fig. 4). The other type of the solution (cardioid) has a greater curvature More exact comparison with experiments is not possible because of the absence of experimental data.

Numerical experiments with the model for inclined jets show that also for $\theta \neq 90^{\circ}$ two different types of solution can be obtained. The most interesting is the solution corresponding to the model-TI. In dependence on the angle $\theta$, the switching point $A$ can have different positions. If the angle $\theta$ decreases, then the part of the film, which does not produce droplets, can increase. There exist also values of parameters at which the point $A$ does not appear (see Fig. $7)$.

It would be interesting to repeat Taylor's experiments in the case of inclined jets. Then it would be possible to check whether the effects observed in the numerical experiments can happen in the practice or not.

The most important question here is, how to manage different possible regimes. The situation becomes more complicated if the liquid film interacts with some 3D structure. It seems that there are still different interesting problems to be solved.

\section{Acknowledgements}

I would like to thank H. Neunzert and K. Steiner for given possibilities to work on this topic and for helpful conversations. I would also like to acknowledge O. Iliev for continuous interest and support during all steps of work on this paper. 


\section{REFERENCES}

[1] H.S. Couto and D. Bastos-Netto. Modeling droplet size distribution from impinging jets. J. of Propulsion and Power, 7, $654-656,1991$.

[2] N. Dombrowski and W.R. Johns. The aerodynamic instability and disintegration of viscous liquid sheets. Chemical Engineering Science, 18, 203 - 214, 1963.

[3] E.A. Ibrahim and A.J. Przekwas. Impinging jets atomization. Phys. Fluids, A3, 12, $2981-2987,1991$.

[4] W.H. Lai, W. Huang and T.L. Jiang. Characteristic study on the like-doublet impinging jets atomization. Atomization and Sprays, 9, 277 - 289, 1999.

[5] H.M. Ryan, W.E. Anderson, S. Pal and R.J. Santoro. Atomization characteristics of impinging liquid jets. Journal of Propulsion and Power, 11, 135 - 145, 1995.

[6] Y.-B. Shen and D. Poulikakos. Thickness variation of a liquid sheet formed by two impinging jets using holographic interferometry. Transactions of the ASME, Journal of Fluid Engineering, 120, 482 - 487, 1998.

[7] A. Sommerfeld. Vorlesungen ueber Theoretische Physik, Band 2: Mechanik der deformierbaren Medien. Frankfurt/M: Verlag Harri Deutsch, 1978.

[8] G.I. Taylor. The dynamics of thin sheets of fluid I. Water bells. Proc. R. Soc. London Ser. A, 253, $289-295,1959$.

[9] G.I. Taylor. The dynamics of thin sheets of fluid II. Waves on fluid sheets. Proc. $R$. Soc. London Ser. A, 253, 296 - 312, 1959.

[10] G.I. Taylor. The dynamics of thin sheets of fluid III. Disintegration of fluid sheets. Proc. R. Soc. London Ser. A, 253, 313 - 321, 1959.

[11] G.I. Taylor. Formation of thin flat sheets of water. Proc. R. Soc. London Ser. A, 259, $1-17,1960$.

[12] E.W. Weisstein. CRC concise encyclopedia of mathematics. Boca Raton, Fla.: CRC Press, 1999.

\section{Apie skysto filmo sąveiką su kliūtimi}

\section{A. Zemitis}

Darbe nagrinejjami skysto filmo, gaminamo purškiamomis srovėmis, matematiniai modeliai. Šie modeliai teisingi esant specialioms prielaidoms apie procesą. Tiriama skysto filmo sąveika su tam tikra kliūtimi. Apibendrinami egzistuojantys modeliai, skysto filmo kokybiniai pokyčiai tiriami naudojant skaitinius eksperimentus. G.I. Taylor [Proc. R.Soc.London Ser. A253, 313(1959)] ịrodè, kad purškiamų sroviu metodu generuotas skystas filmas yra labai jautrus laido, kuris buvo naudojamas kaip klūtis, savybèms. Šio darbo tikslas yra pasiūlyti Teiloro modelio modifikaciją, leidżiančią modeliuoti filmo pavidalą tais atvejais, kada kampas tarp sroviụ gali būti $180^{\circ}$. Skaitiniai rezultatai, gaunami taikant minimus modelius, duoda du skirtingus skysto filmo vaizdus, panašius i tuos, kurie gaunami Teiloro eksperimentuose. Šie du pavidalai priklauso nuo to, kaip arti kliūties yra gaunami lašeliai. Skirtumas tarp jų tuo didesnis, kuo mażesnis kampas tarp srovių. Tokių dviejų reżimų egzistavimas gali turèti esminès įtakos kai kuriems purškiamų srovių taikymams tais atvejais, kada gaminami filmai turi kontaktą su kliūtimis. 